\title{
Dose-dependent effects of intravenous lorazepam on cardiovascular activity, plasma catecholamines and psychological function during rest and mental stress
}

\author{
Johanna H.M. Tulen ${ }^{1,2}$, Peter Moleman ${ }^{1}$, Frans Boomsma ${ }^{3}$, Huibert G. van Steenis ${ }^{2,4}$, \\ and Venantius J.H.M. van den Heuij ${ }^{1}$ \\ ${ }^{1}$ Department of Psychiatry and ${ }^{2}$ Section Pathophysiology of Behavior, ${ }^{3}$ Department of Internal Medicine I and \\ ${ }^{4}$ Department of Clinical Neurophysiology, University Hospital Dijkzigt and Erasmus University Rotterdam, \\ Dr. Molewaterplein 40, NL-3015 GD Rotterdam, The Netherlands
}

Received October 29, 1990 / Final version February 21, 1991

\begin{abstract}
Dose-dependent effects of intravenously administered lorazepam on psychophysiological activity during rest and mental stress were studied in order to examine differential responses to doses which may induce anxiolysis or sedation. In a double-blind randomized cross-over study, nine male volunteers participated in a placebo and a lorazepam session, during which the subjects repeatedly performed a 10 -min version of the Stroop Color Word Test (CWT), with 10 min of rest between the CWTs. Lorazepam was administered before each rest period in increasing doses of $0.0,0.06,0.13,0.25$ and $0.5 \mathrm{mg}$ (total cumulative dose: $0.94 \mathrm{mg}$ ). Heart rate showed a dose-dependent decrease during rest with an $\mathrm{ED}_{50}$ of $0.13 \mathrm{mg}$ lorazepam, while lorazepam had no effect on the cardiovascular and plasma catecholamine response magnitudes to the CWT. Subjective fatigue and reaction time increased significantly after $0.94 \mathrm{mg}$ lorazepam, while at the same dose vigor decreased; state anxiety after the CWT was not influenced by lorazepam. These data show differential effects of lorazepam on cardiovascular, biochemical and psychological function. While heart rate was suppressed at low doses during rest and reaction time and subjective fatigue increased at doses which induced sedation, state anxiety and physiological response patterns to the CWT were not influenced by lorazepam.
\end{abstract}

Key words: Lorazepam IV - Catecholamines - Blood pressure - Heart rate - Performance tasks - Subjective mood

Anxiety is an emotional state in which psychic distress is associated with widespread physiological and biochemical changes, induced primarily by activation of the sympathetic adrenal-medullary system (Lader and Bruce 1986). In order to study the specificity of the relation between sympathetic adrenal-medullary activity and

Offprint requests to: J.H.M. Tulen psychological function during anxiety or stress, controlled situations are needed in which anxiety or stress are induced experimentally. The usefulness of the Stroop Color Word Test (CWT) as a stress-inducing performance task has been shown previously (Frankenhaeuser and Johansson 1976; Hjemdahl et al. 1984; Tulen et al. 1989). The CWT induces sympathetic adrenal-medullary activation as shown by increased cardiovascular activity and catecholamine secretion, in addition to psychic distress (Tulen et al. 1989). However, whether specific mechanisms related to anxiety, a non-specific increase in arousal or activation of effort mechanisms necessary to cope with the task (Sanders 1983) are responsible for the observed reactions is not clear. In order to analyse the mechanisms responsible for the responses to the CWT, administration of anxiolytic drugs may prove to be helpful. The benzodiazepines are the preferred anxiolytic drugs used today and induce different pharmacological effects at different dose levels: anxiolysis at low doses and sedation or sleep at higher doses (Geller and Seifter 1960). Suppression of sympathetic nervous system activity by benzodiazepines has been observed in man at doses which induce sedation (Duka et al. 1986; Roy-Byrne et al. 1988). These effects might, however, be different at doses which induce anxiolysis. It is therefore of interest to study specific dose-dependent sympathetic adrenalmedullary effects in relation to rest levels and stressinducing performance tests.

In this study we investigated the cumulative doseresponse effects of intravenously administered lorazepam during rest and during presentation of the CWT in a placebo-controlled design in healthy male volunteers. Lorazepam was chosen because of its short distribution half-life (intravenous: $\pm 4 \mathrm{~min}$; Greenblatt et al. 1977) which allowed us to create a cumulative dose-response curve with five different doses within one experimental session. In addition, lorazepam has no active metabolites (Kyriakopoulos et al. 1978) which could complicate the interpretation of data. Five doses were administered, resulting in a total cumulative dose of ca. $1 \mathrm{mg}$ lorazepam. The oral dose-equivalent of $1 \mathrm{mg}$ lorazepam IV 
is circa $2 \mathrm{mg}$ : a dose which has sedative effects (Patat et al. 1987; Preston et al. 1989). By studying the dosedependency of effects of lorazepam IV on sympathetic adrenal-medullary activity and psychological function during rest and CWT, differential responses related to anxiolysis and sedation during rest and mental stress were explored.

\section{Materials and methods}

\section{Subjects, design and procedure}

Nine male volunteers (mean: 23.9 years, range: $21-29$ ) participated in a randomized double-blind cross-over study in two experimental sessions each: a placebo (PLA) and a lorazepam (LOR) session. The study was approved by the Medical Ethical Committee of the University Hospital Dijkzigt. All subjects gave written informed consent and were paid for their participation in the study. The subjects underwent a medical screening: all were in good physical condition. Six of the nine subjects were non-smokers, three subjects smoked moderately ( $<5$ cigarettes per day); heavy drinking was not reported.

During both sessions the subjects performed on five consecutive occasions a 10-min version of the Stroop Color Word Test (CWT), with $10 \mathrm{~min}$ of rest between the CWTs. Each CWT was followed by a Simple Reaction Time task (SRT) (duration of task: $5 \mathrm{~min}$ ). A schematic time-bar of the experimental procedures during each session is shown in Fig. 1. During the PLA session, a PLA injection $(2.5 \mathrm{ml}$ saline, slowly injected over $1 \mathrm{~min})$ was administered five times intravenously, each time before the rest periods. During the LOR session, LOR was administered intravenously (in $2.5 \mathrm{ml}$ saline solution, slowly injected over $1 \mathrm{~min}$ ) before each rest period in increasing doses of $0.0 \mathrm{mg}, 0.0625 \mathrm{mg}, 0.125 \mathrm{mg}, 0.25 \mathrm{mg}$ and $0.5 \mathrm{mg}$ (total cumulative dose: $0.9375 \mathrm{mg}$ ). Lorazepam has a distribution half-life (intravenous) of about $4 \mathrm{~min}$; within $15 \mathrm{~min}$ a distribution of $>95 \%$ is reached (Greenblatt et al. 1977) and its elimination half-life is about 12-13 h (Kyriakopoulos et al. 1978; Boulenger et al. 1984). The consecutive doses of LOR used in this study can therefore be supposed to induce a cumulative effect.

The two experimental sessions per subject were recorded on separate days, I week apart. The subjects were requested to abstain from coffee, tea and smoking on both days, from the moment they got out of bed in the morning until they arrived in the laboratory. During the experimental sessions coffee, tea and smoking were not allowed. Before the start of each session, the subjects were requested to void urine and drink a glass of mineral water. Each session lasted from 09:00 to 12:30 hours: physiological, biochemical and psychological measurements were performed during this period. The subjects were sitting in a comfortable chair during the entire session. After the session, a standard light lunch was served. Because sedative effects are observed after an intravenous cumulative dose of $1 \mathrm{mg} \mathrm{LOR}$, in the afternoon the subjects remained in the hospital in a room where they could read or study. At 18:00 hours they were allowed to go home, after approval by the MD.

\section{Tests}

The Stroop Color Word Test (CWT). The CWT consists of four words (red, green, blue, yellow) which are presented on videotape, one word at a time, in four different colors (red, green, blue, yellow). The stimulus presentation and the interstimulus interval last about $1.5-2.0 \mathrm{~s}$ and conform to previously described versions of this test (Frankenhaeuser and Johansson 1976; Tulen et al. 1989). The subject has to indicate the color of the word on an answer sheet, with the specific request to do their very best and make as few errors as possible. The test induces a cognitive conflict (Stroop 1935), while time-pressure effects are added due to the rapid presentation of the stimuli. Within each session, five different 10 -min versions of the CWT were used to avoid learning effects concerning word sequence. The number of errors made during each CWT was counted; the percentage of errors per CWT was calculated relative to the total number of stimuli presented. In order to become familiar with the specific requirements of the task, a 2 -min practice tape was presented at the beginning of the first session for instruction purposes.

Simple Reaction Time Task (SRT). A 5-min version of a visual reaction-time task was presented on a Personal Computer (Olivetti) The subject was requested to press a button as soon as possible after a small red square appeared on the monitor. The interstimulusinterval varied randomly between 1 and $5 \mathrm{~s}$ in order to avoid stimulus anticipation effects. Reaction time was calculated with an accuracy of $1 \mathrm{~ms}$.

\section{Recordings}

Psychological. Before and after the whole session and immediately after each CWT, changes in subjective mood were assessed by means of a shortened version of the vigor and fatigue subscales of the Profile Of Mood States (POMS) (McNair et al. 1971) which was validated for the Dutch population (Wald and Mellenbergh 1990) and a shortened state version of the State-Trait Anxiety Inventory (STAI) (van der Ploeg et al. 1980; Knippenberg et al. 1990).

Physiological. A Nihon Kohden polygraph was used to amplify and calibrate the physiological signals. All signals were monitored continuously on paper by means of a Stemens Elema EEG mingograf, and at the same time recorded analogue on a Racal instrumentation recorder. The ECG was derived using a precordial lead. Blood pressure was recorded using a servo-plethysmo-manometer for continuous, non-invasive measurement of finger arterial blood pressure, employing the volume clamp technique of Peňáz (Peňáz et al. 1976; Wesseling et al 1982; Settels and Wesseling 1985) (Finapres 2300 NIBP monitor, Ohmeda systems).

ECG and blood pressure recordings were digitized with a sample frequency of $102.4 \mathrm{~Hz}$ on a Personal Computer (Olivetti), connected to a Labmaster Analogue/Digital converter. Before A/D conversion a Schmitt trigger was used to trigger the incidence of the $R$-waves in the ECG; the output pulses of the trigger were fed into the converter for sampling. The time between the output pulses (interbeat interval) was measured with a resolution of $10 \mathrm{~ms}$. Systolic, diastolic and mean blood pressure (SBP, DBP, MBP) were defined

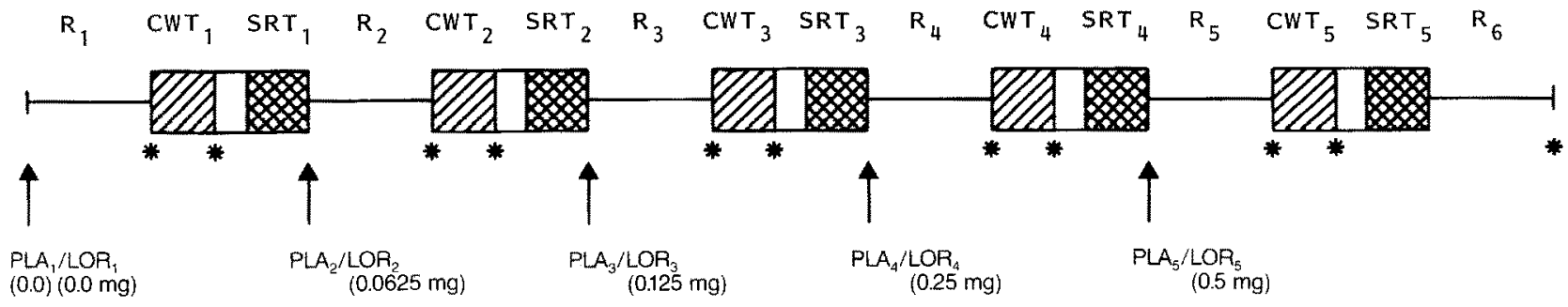

Fig. 1. Schematic time-bar of the experimental procedures during the PLA and the LOR session. Injection moment ( $\uparrow$ ); $C W T(h a t c h e d)$ : Color Word Test; POMS : Profile Of Mood States, STAI: State-Trait Anxiety Inventory (blank); SRT (cross-hatched): Simple Reaction Time task; PLA: placebo; LOR: lorazepam; $R(-)$ : rest period; blood sample $\left(^{*}\right)$ 
per $\mathrm{R}-\mathrm{R}$ interval of the $\mathrm{ECG}$ with a resolution of $0.2 \mathrm{mmHg}$. Obtaining blood samples caused momentary increases in heart rate and blood pressure and induced some movement artifacts: these periods were excluded from the analyses. One blood pressure recording showed technical shortcomings and was not analysed. Mean heart rate (in BPM) and mean SBP, DBP and MBP were calculated per rest period and for the first 5 min of each CWT. Only heart rate and MBP data will be presented because SBP and DBP data showed the same effects as MBP.

Biochemical. Forty-five minutes before the start of the recordings, a catheter (Venflon, 18G, Viggo AB, Helsingborg, Sweden) was inserted in an antecubital vein of the non-dominant forearm, through which blood samples were drawn and infusion of LOR/ PLA took place. Blood samples $(8 \mathrm{ml}$ per sample) were drawn the end of each rest period and during the second half of each CWT (the last $5 \mathrm{~min}$ ) and collected in heparinized tubes containing $12 \mathrm{mg}$ gluthathione for assay of catecholamines. The tubes were immediately placed on ice and centrifuged within $15 \mathrm{~min}$. Plasma was subsequently frozen at $-70^{\circ} \mathrm{C}$. The catecholamines were assayed by means of high-performance liquid chromatography with fluorimetric detection (Van der Hoorn et al. 1989). The limits of detection for adrenaline and noradrenaline were $0.3 \mathrm{pg}$, with a low coefficient of variation $(3-7 \%)$.

\section{Statistical analyses}

All analyses are presented for $N=9$ with the exception of the blood pressure analyses $(N=8)$. For the physiological and biochemical data, two-tailed Student's $t$-tests were used for pairwise comparisons of the first rest periods of the two sessions to establish similarity of baseline values. Effects of LOR or PLA on rest values and CWT response magnitudes were analysed separately. CWT response magnitude was defined as the difference in heart rate, blood pressure or catecholamines during the CWT and the preceding rest period. One-factor analyses of variance for repeated measurements were performed within each condition (LOR or PLA), to analyse specific dose effects (LOR condition: factor Dose) or learning/habituation effects (PLA condition: factor Time). In order to assess the effect of the cumulative doses of LOR the factor of increase in doses was taken into account to contrast between the successive rest periods or CWT responses (factor for contrast between the five dosages: $0,1,2,4,8$ ).
Dose-related changes in subjective fatigue, vigor or anxiety were analysed per condition (LOR or PLA) with a nonparametric onefactor analysis of variance (Friedman) (Siegel 1956), while Wilcoxon tests (Siegel 1956) were applied for pairwise comparisons between the different dose levels within each condition.

Where appropriate, dose-response curves were constructed and presented graphically, using the mean response of all individuals for each dose. $\mathrm{ED}_{50} \mathrm{~s}$ were calculated for each individual per variable, using linear interpolation. Paired Student's $t$-tests were used to compare $\mathrm{ED}_{50} \mathrm{~s}$ of the different responses.

\section{Results}

\section{Cardiovascular activity and plasma catecholamines}

Table 1 and Figs. 2 and 3 present the dose-related effects of lorazepam on cardiovascular activity and plasma catecholamines during rest and CWT, in relation to the placebo administrations.

Rest periods. Baseline values of the PLA and LOR sessions were similar for heart rate $(t=-1.61 ; P=0.15)$, MBP $(t=0.69 ; P=0.51)$; plasma adrenaline $(t=-1.25$; $P=0.24)$ and plasma noradrenaline $(t=-2.11$; $P=0.07$ ).

The analyses of variance indicated a significant Dose effect for heart rate in the LOR session (Table 2). After a cumulative dose of $0.19 \mathrm{mg}$ LOR (LOR3) heart rate during rest decreased significantly in comparison with the first rest period (R1) $(t=4.95 ; P=0.001)$ (Fig. 2). This effect appears to be a specific effect of LOR, since no Time effect was observed in the PLA session (Table 2).

With regard to $\mathrm{MBP}$, a significant Time effect was observed in the PLA session (Table 2), indicating an increase in MBP in time. Increased values were observed mainly in the last two rest periods (R5 and R6, Fig. 2), the difference between $\mathrm{R} 1$ and $\mathrm{R} 5$ being significant
Table 1. Mean (SD) values of the cardiovascular data and the plasma catecholamine levels during the consecutive rest periods (R1-R6) and the CWT response magnitudes (CWT1-CWT5) of the
LOR and PLA session. HRT: heart rate, MBP: mean blood pressure, ADR: adrenaline, NOR: noradrenaline

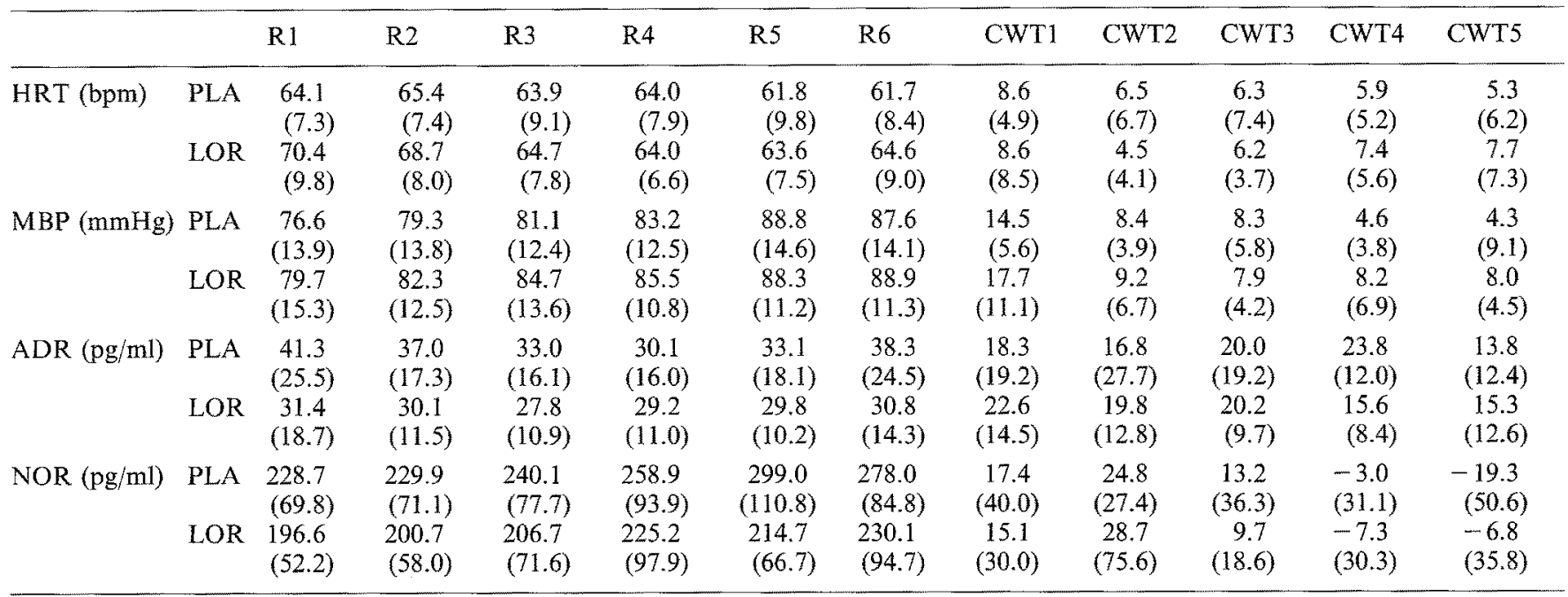



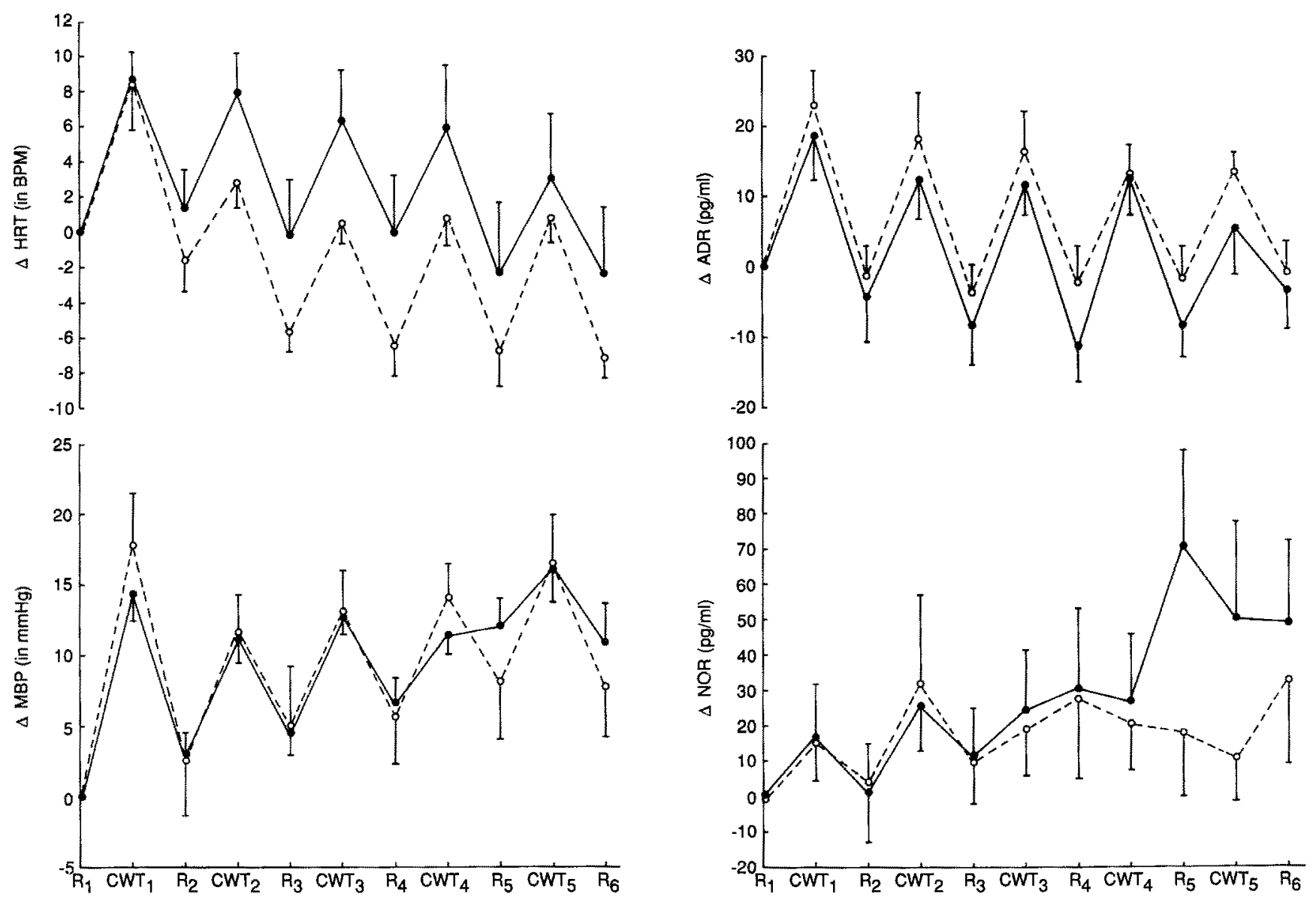

Fig. 2, Dose-related effects of lorazepam IV $(0 \ldots \ldots)$ on cardiovascular activity during rest and $\mathrm{CWT}$, in comparison with cardiovascular activity during placebo (-—-) administrations. The upper curve presents mean (and SEM) heart rate of the consecutive rest and $C W T$ periods, calculated relative to $R I$ (i.e. baseline: first rest period). The lower curve presents mean $M B P$, relative to $R I$ (see also Fig. 1)

Fig. 3. Dose-related effects of lorazepam IV on plasma catecholamines during rest and CWT, in comparison with plasma catecholamines during placebo administrations. (see legend to Fig. 2 for explanation). $A D R=$ adrenaline. $N O R=$ noradrenaline

Table 2. Analyses of variance for repeated measures on the cardiovascular and biochemical data: $F$-values and level of significance $(P)$ of the within-subject effects of the main factor DOSE (injection 1-5) during the lorazepam session and the main factor Time during the placebo session are presented. Level of significance and $F$-values of the between-subjects effects are also indicated. The analyses were performed on the rest periods and the CWT response magnitudes separately. HRT: heart rate; MBP; mean blood pressure; ADR: adrenaline; NOR: noradrenaline

\begin{tabular}{|c|c|c|c|c|c|c|c|c|c|}
\hline & & \multicolumn{4}{|c|}{ Rest periods } & \multicolumn{4}{|c|}{ CWT response magnitude } \\
\hline & & \multicolumn{2}{|c|}{ Lorazepam } & \multicolumn{2}{|c|}{ Placebo } & \multicolumn{2}{|c|}{ Lorazepam } & \multicolumn{2}{|c|}{ Placebo } \\
\hline & & Dose & Subject & Time & Subject & Dose & Subject & Time & Subject \\
\hline HRT & $\begin{array}{l}\mathrm{F} \\
P \leq\end{array}$ & $\begin{array}{l}7.62 \\
0.001\end{array}$ & $\begin{array}{c}716.78 \\
0.001\end{array}$ & $\begin{array}{l}0.54 \\
0.710\end{array}$ & $\begin{array}{c}773.69 \\
0.001\end{array}$ & $\begin{array}{l}1.11 \\
0.370\end{array}$ & $\begin{array}{c}19.76 \\
0.002\end{array}$ & $\begin{array}{l}1.13 \\
0.358\end{array}$ & $\begin{array}{c}13.77 \\
0.006\end{array}$ \\
\hline $\mathrm{MBP}$ & $\begin{array}{l}\mathrm{F} \\
P \leq\end{array}$ & $\begin{array}{l}2.28 \\
0.085\end{array}$ & $\begin{array}{c}424.21 \\
0.001\end{array}$ & $\begin{array}{c}17.78 \\
0.001\end{array}$ & $\begin{array}{c}308.55 \\
0.001\end{array}$ & $\begin{array}{l}6.00 \\
0.001\end{array}$ & $\begin{array}{c}26.62 \\
0.001\end{array}$ & $\begin{array}{l}6.36 \\
0.001\end{array}$ & $\begin{array}{c}27.61 \\
0.001\end{array}$ \\
\hline ADR & $\begin{array}{l}F \\
P \leq\end{array}$ & $\begin{array}{l}0.33 \\
0.855\end{array}$ & $\begin{array}{c}62.55 \\
0.001\end{array}$ & $\begin{array}{l}2.23 \\
0.088\end{array}$ & $\begin{array}{c}36.93 \\
0.001\end{array}$ & $\begin{array}{l}0.91 \\
0.474\end{array}$ & $\begin{array}{c}35.74 \\
0.001\end{array}$ & $\begin{array}{l}0.50 \\
0.737\end{array}$ & $\begin{array}{c}19.15 \\
0.002\end{array}$ \\
\hline NOR & $\begin{array}{l}\mathrm{F} \\
P \leq\end{array}$ & $\begin{array}{l}1.08 \\
0.382\end{array}$ & $\begin{array}{c}93.88 \\
0.001\end{array}$ & $\begin{array}{l}4.93 \\
0.003\end{array}$ & $\begin{array}{c}92.30 \\
0.001\end{array}$ & $\begin{array}{l}0.88 \\
0.490\end{array}$ & $\begin{array}{l}4.73 \\
0.066\end{array}$ & $\begin{array}{l}2.39 \\
0.074\end{array}$ & $\begin{array}{l}0.74 \\
0.418\end{array}$ \\
\hline
\end{tabular}

$(t=-7.22 ; P<0.001)$. This increasing trend was not present in the LOR session.

LOR had no effect on the plasma adrenaline levels; trends during the PLA session were not observed (Table 2).

Figure 3 indicates a gradual increase in plasma noradrenaline levels during rest in the PLA session (especially during R5), which was not present in the LOR session.
The Time effect for plasma noradrenaline levels during the PLA session was significant (Table 2).

CWT responses. The response magnitudes to CWT1 of the LOR and PLA session were similar for heart rate $(t=-0.02 ; P=0.98), \operatorname{MBP}(t=-0.76 ; P=0.47)$, plasma adrenaline $(t=0.81 ; P=0.45)$ and plasma noradrenaline $(t=-0.06 ; P=0.95)$. 
There were no differences in heart rate responses to the consecutive CWTs in the PLA-session (factor Time: ns, Table 2), nor did LOR affect the response to the CWT (factor Dose: ns, Table 2).

A decrease in response magnitude was observed for MBP, both in the PLA session (a significant Time effect, Table 2) and in the LOR session (a significant Dose effect, Table 2), indicating learning or habituation effects to the CWT within each condition, but no drug-specific effects (Fig. 2).

LOR had no effect on the plasma catecholamine response magnitudes to the CWTs (Table 2). Figure 3 shows an increase in plasma noradrenaline secretion during CWT1, CWT2 and CWT3 in relation to the preceding rest periods. However, thereafter a negative noradrenaline response is observed during CWT4 and CWT5.

In summary, during the rest periods the only effect of LOR was a dose-dependent decrease in heart rate; cardiovascular and plasma catecholamine response magnitudes to the CWT were not influenced by LOR. Nearly all variables showed significant (between) subject effects, indicating large interindividual variability (Tables 1 and 2).

\section{Performance on tasks and subjective mood}

$S R T$. In Fig. 4 the dose-dependent effects of LOR on reaction time to the five consecutive SRTs are presented.

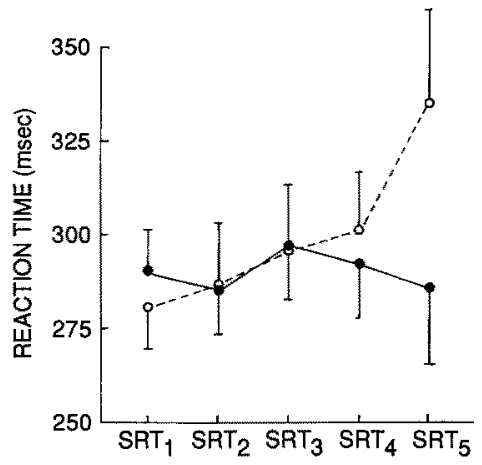

Fig. 4. Dose-related effects of lorazepam (O-..-o) on simple reaction time, in comparison with simple reaction time to placebo (-) administrations. Mean (and SEM) reaction time in $\mathrm{ms}$ as measured during the five consecutive SRTs of the LOR and PLA session
Reaction time to SRT1 of the LOR and PLA session was similar $(t=0.95 ; P=0.37)$. A gradual increase in reaction time was observed in the LOR session (factor Dose: $F=4.99, P=0.003$; Subject: $F=392.64, P<0.001)$, but not in the PLA session (factor Time: $F=0.49, P=0.74$; Subject: $F=408.38, P<0.001$ ), which indicates a specific drug effect. Reaction time was significantly increased after a cumulative dose of $0.94 \mathrm{mg}$ LOR (SRT1-LOR versus SRT5-LOR: $t=2.58 ; P=0.03$; SRT5-LOR versus SRT5-PLA: $t=4.60 ; P=0.001$ ) (Fig. 4 ).

$C W T$ performance. The percentage of errors to the CWTs of the PLA session decreased from $6.7 \%$ during CWT1 to $4.8 \%$ during CWT5 (non-significant difference). During the LOR session the percentage of errors was similar from CWT1 (6.6\%) to CWT4 (5.2\%), but increased significantly during CWT5 $(17.1 \% ; t=-5.02$, $P=0.001)$ in comparison with CWT1.

Subjective mood. Table 3 indicates the changes in fatigue, vigor and anxiety, as assessed immediately after each CWT, during the LOR and the PLA sessions. During the LOR session, we observed a gradual increase in fatigue: after a cumulative dose of $0.94 \mathrm{mg}$ LOR (LOR5), this increase was significant in comparison with the baselinevalues $(z=-2.20 ; P=0.02)$. Similarly, a significant decrease in vigor was observed after a cumulative dose of $0.94 \mathrm{mg}$ LOR (LOR5) in comparison with baseline values $(z=-2.49 ; P=0.01)$. Within-session analyses revealed a significant Dose effect during the LOR session for both fatigue and vigor, but no effect at all on state anxiety.

\section{Dose-response curves}

Figure 5 shows the dose-response curves for heart rate, $\mathrm{SRT}$, fatigue and vigor. The $\mathrm{ED}_{50} \mathrm{~s}$ calculated on the basis of the individual dose-response curves were $0.13 \mathrm{mg} \pm 0.06$ (mean $\pm \mathrm{SD}, N=9$ ) for heart rate, $0.32 \pm 0.23(N=8)$ for SRT, $0.24 \pm 0.27(N=7)$ for vigor and $0.47 \pm 0.17(N=7)$ for fatigue. Two individuals did not show a response on the vigor and fatigue scales and therefore were excluded from the analysis. Paired Student's $t$-tests revealed a significant difference between the $E D_{50}$ s for heart rate versus fatigue $(t=-5.27$, $P=0.002, N=7$ ). From Fig. 5 it is apparent that the heart rate response has indeed reached a maximum, but this is not the case for the other three variables.
Table 3. Mean and range values of subjective mood (fatigue, vigor, anxiety) for the five consecutive assessments after each CWT during the PLA and the LOR session. Friedman analysis of variance were performed for the PLA and LOR session separately; Chi-square and level of significance ( $P$-values) are indicated per session

\begin{tabular}{|c|c|c|c|c|c|c|}
\hline & \multicolumn{2}{|l|}{ Fatigue } & \multicolumn{2}{|l|}{ Vigor } & \multicolumn{2}{|c|}{ State anxiety } \\
\hline & $\begin{array}{l}\text { PLA } \\
\text { session }\end{array}$ & $\begin{array}{l}\text { LOR } \\
\text { session }\end{array}$ & $\begin{array}{l}\text { PLA } \\
\text { session }\end{array}$ & $\begin{array}{l}\text { LOR } \\
\text { session }\end{array}$ & $\begin{array}{l}\text { PLA } \\
\text { session }\end{array}$ & $\begin{array}{l}\text { LOR } \\
\text { session }\end{array}$ \\
\hline 1 & $7.2(3)$ & $7.2(4)$ & $17.6(11)$ & $18.2(15)$ & $13.0(6)$ & $12.7(5)$ \\
\hline 2 & $7.0(2)$ & $7.1(3)$ & $17.9(11)$ & $17.1(10)$ & $12.8(3)$ & $13.0(4)$ \\
\hline 3 & $7.2(3)$ & $7.8(7)$ & $17.4(10)$ & $16.3(9)$ & $12.8(6)$ & $13.0(8)$ \\
\hline 4 & $6.9(3)$ & $8.6(8)$ & $17.2(10)$ & $15.9(9)$ & $12.9(5)$ & $13.8(9)$ \\
\hline 5 & $7.9(8)$ & $10.2(13)$ & $15.6(10)$ & $14.3(13)$ & $13.6(4)$ & $12.9(7)$ \\
\hline $\mathrm{Chi}^{2}$ & 0.7 & 12.2 & 4.5 & 10.6 & 1.8 & 3.5 \\
\hline$P \leq$ & 0.95 & 0.01 & 0.34 & 0.03 & 0.78 & 0.48 \\
\hline
\end{tabular}




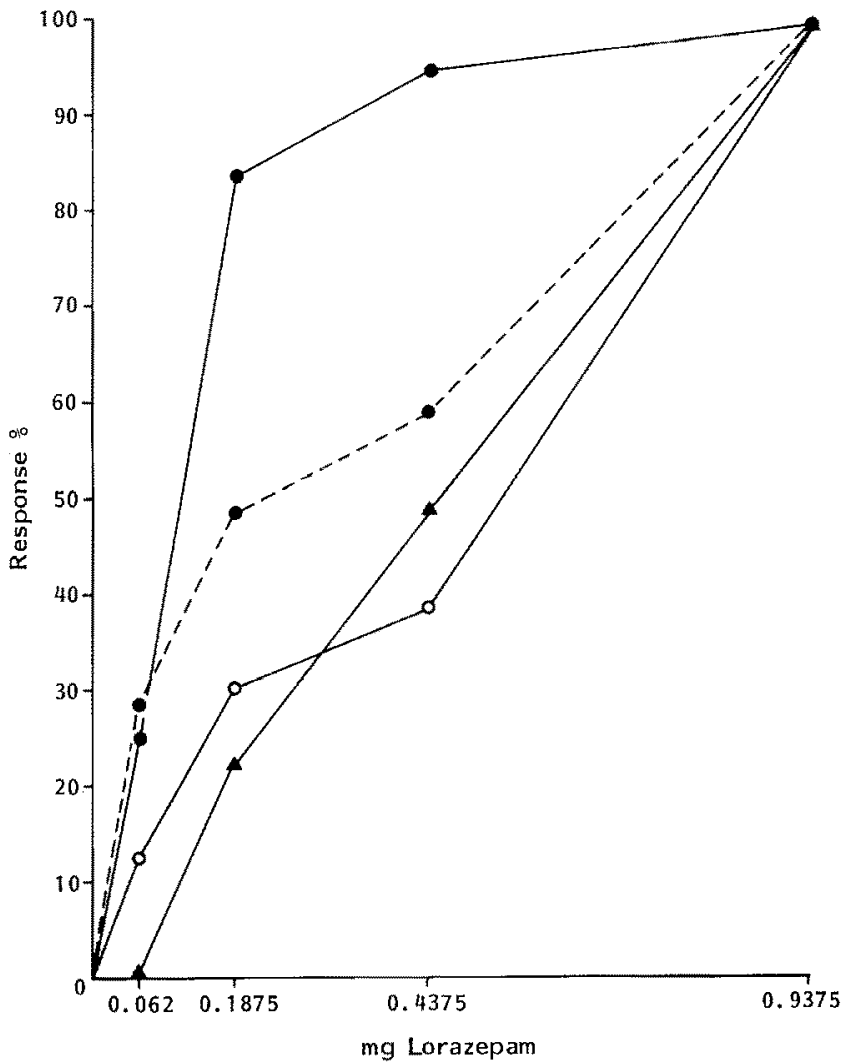

Fig. 5. Mean $(N=9)$ cumulative dose-response curves of LOR on heart rate $(\bullet-)$ ) during rest, fatigue $(\mathbf{\Lambda}-\mathbf{\Lambda})$, vigor $(\bullet-.-\bullet)$ and reaction time (SRT) $(\mathrm{O}-0) . \quad Y$-axis: heart rate (HRT) and vigor: \% reduction; SRT and fatigue: \% increase

Therefore, the $\mathrm{ED}_{50} \mathrm{~s}$ for SRT, fatigue and vigor are probably underestimated, as is also illustrated by the fact that two individuals did not yet show a response on the fatigue and vigor scale after a cumulative dose of $0.94 \mathrm{mg}$ LOR.

To summarize the results:

1. Heart rate during rest was reduced dose-dependently with an $\mathrm{ED}_{50}$ of $0.13 \mathrm{mg}$ LOR.

2. LOR induced an increase in SRT $\left(\mathrm{ED}_{50}>0.32\right)$ and fatigue $\left(E D_{50}>0.47\right)$ and a decrease in vigor $\left(E D_{50}>0.24\right)$. The $E D_{50}$ of subjective fatigue was significantly higher than the $E D_{50}$ of heart rate during rest.

3. The CWT induced consistent increases in heart rate and plasma adrenaline levels, but LOR had no effect on the heart rate, MBP or catecholamine response magnitudes to the CWT.

4. LOR had no effect on state anxiety, or on MBP or plasma catecholamines, although a gradual increase in MBP and plasma noradrenaline was observed during the rest periods of the PLA session.

\section{Discussion}

The aim of the present study was to separate sedative responses to lorazepam from anxiolytic responses which are supposed to occur at lower doses than sedative re- sponses and to link either of these responses to effects on sympathetic adrenal-medullary activity.

Our results show a clear sedative effect of lorazepam as expressed by increased reaction time, increased number of errors on the CWT, increased fatigue and decreased vigor. Performance impairment, reduced attention or sedation have been described after an oral dose of $2 \mathrm{mg}$ LOR (Patat et al. 1987; Preston et al. 1989). In our study most of these responses occurred with an $\mathrm{ED}_{50}$ of $0.24 \mathrm{mg}$ intravenously or higher, which is probably equivalent to an oral dose of approximately $0.5 \mathrm{mg}$ or higher.

Anxiolytic responses, however, were not observed as no effect of LOR on state anxiety or on any of the responses to the CWT could be detected, irrespective of the fact that the CWT reproducibly induced an increase in heart rate and plasma adrenaline levels. One might argue that the CWT as a stress-inducing performance task did not induce a relevant increase in anxiety in these healthy (non-anxious) volunteers and that therefore an anxiolytic effect of LOR could not be demonstrated. This is in line with the findings of File and Lister (1985), who report a failure of LOR to reduce experimentallyinduced anxiety after oral doses of 1 and $2.5 \mathrm{mg}$.

Since no subjective anxiety, or any effects of LOR on responses to the CWT were observed, the heart rate and adrenaline responses to each CWT may reflect an increase in effort mechanisms (Sanders 1983), which are necessary for the subject to cope with the task, rather than stress- or anxiety-related responses. Compensatory mechanisms as a result of subjective sedation may have partly masked a suppressing effect of LOR on the response magnitudes to the CWT, since motivation to perform a task is not negatively influenced by doses of LOR which induce sedation (File and Lister 1982). In order to establish whether the heart rate or adrenaline responses to the CWT are part of effort mechanisms necessary to perform a task, compensation mechanisms to overcome sedation, or stress-response mechanisms on which LOR has no influence, application of anxiolytics without sedative properties (such as buspirone; Cohn and Wilcox 1986) or anxiolytics with a specific influence on plasma catecholamines (such as alprazolam; Grant et al. 1984) should be studied in a placebo-controlled design.

Evidence of direct or indirect involvement of the central benzodiazepine pathways in the regulation of sympathetic nervous system activity is scarce. Some studies report normal or increased heart rate after oral administration of $1-2.5 \mathrm{mg}$ LOR (Elliott et al. 1970; File and Lister 1985), but other studies have shown a suppression of plasma catecholamine levels and blood pressure by benzodiazepines at doses which induce sedation (Duka et al. 1986; Roy-Birne et al. 1988, 1989). Our data are in agreement with these last observations since a cumulative dose of $0.94 \mathrm{mg}$ LOR, which significantly induced subjective sedation, also suppressed plasma noradrenaline and MBP levels during rest. However, we found that heart rate already was reduced at lower doses with an $E D_{50}$ of $0.13 \mathrm{mg}$ intravenously. Since plasma catecholamines and blood pressure were unaffected at 
these doses of LOR, this effect may reflect an increase in vagal stimulation of the heart, rather than a suppression of sympathetic activity. This effect occurred at dosages expected to exert an anxiolytic effect and not sedative effects. Whether it is indeed related to vagal stimulation and clinical anxiolysis, however, could not be established in the present experiment and awaits further studies.

Acknowledgements. The authors would like to thank Prof. Dr. L. Pepplinkhuizen (Department of Psychiatry) for his comments on a draft of this manuscript and A. de Lijster and R. Vermaat for technical assistance during the study. Dr. P.J. Blankestijn (Department of Internal Medicine l) performed the medical screening of the subjects. Dr. H. Emmen (Medisch Biologisch Laboratorium TNO, Rijswijk) kindly provided the computer software for the Simple Reaction Time Task.

\section{References}

Boulenger J-P, Smokcum R, Lader M (1984) Rate of increase of plasma lorazepam concentrations: absence of influence upon subjective and objective effects. J Clin Psychopharmacol $4[1]: 25-31$

Cohn J, Wilcox CS (1986) Low-sedation potential of buspirone compared with alprazolam and lorazepam in the treatment of anxious patients: a double-blind study. J Clin Psychiatry 47: $409-412$

Duka T, Ackenheil M, Noderer J, Doenicke A, Dorow R (1986) Changes in noradrenaline plasma levels and behavioural responses induced by benzodiazepine agonists with the benzodiazepine antagonist Ro 15-1788. Psychopharmacology $90: 351-357$

Elliott HW, Nomof N, Navarro G, Ruelius HW, Knowles JA, Comer WH (1970) Central nervous system and cardiovascular effects of lorazepam in man. Clin Pharmacol Ther 12:468-481

File SE, Lister RG (1982) Do lorazepam-induced deficits in learning result from impaired rehearsal, reduced motivation or increased sedation? Br J Clin Pharmacol 14:545-550

File SE, Lister RG (1985) A comparison of the effects of lorazepam with those of propranolol on experimentally-induced anxiety and performance. Br J Clin Pharmacol 19:445-451

Frankenhaeuser M, Johansson G (1976) Task demand as reflected in catecholamine excretion and heart rate. J Hum Stress 2:15-23

Geller I, Seifter J (1960) The effects of meprobamate, barbiturates, $d$-amphetamine and promazine on experimentally induced conflict in the rat. Psychopharmacologica 1:482-492

Grant SJ, Mayor R, Redmond DE (1984) Effects of alprazolam, a novel triazolobenzodiazepine, on locus coeruleus unit activity. Neurosci Abstr 10:952

Greenblatt DI, Comer WH, Elliott HW, Shader RI, Knowles JA, Ruelius HW (1977) Clinical pharmacokinetics of lorazepam. III. Intravenous injection. J Clin Pharmacol 17:490-494

Hjemdahl P, Freyschuss U, Juhlin-Dannfelt A, Linde B (1984) Differentiated sympathetic activation during mental stress evoked by the Stroop test. Acta Physiol Scand (Suppl) $527: 25-29$

Knippenberg FEC van, Duivenvoorden HJ, Bonke B, Passchier J (1990) Shortening the State-Trait Anxiety Inventory. J Clin Epidemiol 43[9]:995-1000

Kyriakopoulos AA, Greenblatt DJ, Shader RI (1978) Clinical pharmacokinetics of lorazepam: a review. J Clin Psychiatry 39[10-2]: 16-23

Lader M, Bruce M (1986) States of anxiety and their induction by drugs. Br J Clin Pharmacol 22:251-261

McNair DM, Lorr M, Droppelman LF (1971) Manual for the profile of mood states. Educational and Industrial Testing Service, San Diego

Patat A, Klein MJ, Hucher M (1987) Effects of single oral doses of clobazam, diazepam and lorazepam on performance tasks and memory. Eur J Clin Pharmacol 32:461-466

Peňáz J, Voigt A, Teichmann W (1976) Beitrag zur fortlaufenden indirekten Blutdruckmessung. Z Inn Med 31 : 1030-1033

Ploeg HM van der, Defares PB, Spielberger CD (1980) ZBV. Handleiding bij de Zelf-Beoordelings Vragenlijst. Swets \& Zeitlinger, Lisse

Preston GC, Ward CE, Broks P, Traub M, Stahl SM (1989) Effects of lorazepam on memory, attention and sedation in man: antagonism by Ro 15-1788. Psychopharmacology 97:222-227

Roy-Byrne PP, Lewis N, Villacres C, Greenblatt DJ, Shader RI, Veith RC (1988) Suppression of norepinephrine appearance rate in plasma by diazepam in humans. Life Sci 43:1615-1623

Roy-Byrne PP, Lewis N, Villacres E, Diem H, Greenblatt DJ, Shader RI, Veith R (1989) Preliminary evidence of benzodiazepine subsensitivity in panic disorder. Biol Psychiatry 26:744-748

Sanders AF (1983) Towards a model of stress and human performance. Acta Psychol 53:61-97

Settels JJ, Wesseling KH (1985) Fin. A. Pres: Non-invasive finger arterial pressure waveform registration. In: Orlebeke JR, Mulder G, van Doornen LJP (eds) Psychophysiology of cardiovascular control. Plenum Press, New York, pp 267-283

Siegel S (1956) Nonparametric statistics for the behavioral sciences. McGraw-Hill, Kogakusha Tokyo

Stroop JR (1935) Interference in serial verbal reactions. J Exp Psychol 18:643-661

Tulen JHM, Moleman P, Steenis HG van, Boomsma F (1989) Characterization of stress reactions to the Stroop Color Word Test. Pharmacol Biochem Behav 32[1]:9-15

Van der Hoorn FAJ, Boomsma F, Man in 't Veld AJ, Schalekamp MADH (1989) Determination of catecholamines in human plasma by high-performance liquid chromatography: comparison between a new method with fluorescence detection and an established method with electrochemical detection. J Chromatogr 487:17-28

Wald FDM, Mellenbergh GJ (1990) De verkorte versie van de nederlandse vertaling van de Profile Of Mood States (POMS). Ned T Psychol 45:86 90

Wesseling KH, De Wit B, Settels JJ, Klauwer WH, Arntzenius AC (1982) On the indirect registration of finger blood pressure after Peňáz. Funkt Biol Med 1:245-250 